\title{
O impacto dos metais pesados na patogênese e progressão da doença de Alzheimer
}

\section{The impact of heavy metals in the pathogenesis and progression of Alzheimer's disease}

El impacto de los metales pesados en la patogénesis y progresión de la enfermedad de Alzheimer

Filipe Reis Soares ${ }^{1 *}$, Ranyelle Gomes de Oliveira ${ }^{1}$, Hermínio Maurício da Rocha Sobrinho ${ }^{1,2}$.

\begin{abstract}
RESUMO
Objetivo: Descrever as principais alterações fisiopatológicas causadas pelos Metais Pesados (MP) no organismo humano e sua possível contribuição para o desenvolvimento ou progressão da Doença de Alzheimer (DA). Métodos: Trata-se de uma pesquisa bibliográfica do tipo revisão integrativa de literatura, de caráter exploratório. Foram incluídos artigos publicados no período de 2009 a 2021. Resultados: A exposição crônica a MP tem se tornado mais comum entre a população mundial à medida que o ritmo agressivo das atividades antrópicas libera quantidades excessivas destes no meio ambiente. Especialmente os MP não essenciais perturbam a homeostase dos MP essenciais nos níveis celular, tecidual e orgânico. $\mathrm{O}$ aumento nos níveis corporais de MP afeta a fisiologia e a imunidade do cérebro, bem como podem contribuir para a formação anormal de espécies reativas de oxigênio no sistema nervoso central e ao acúmulo de proteínas tóxicas tais como a proteína $\beta$-amiloide e proteína tau induzindo o processo de neurodegeneração cerebral. Considerações finais: Os MP interagem com a proteína $\beta$-amiloide, prejudicam a função da proteína tau e causam superprodução de mediadores inflamatórios no cérebro, resultando em agregação de placas amiloides no tecido, desestabilização celular e morte neuronal, que podem levar ao início e progressão da DA.
\end{abstract}

Palavras-chave: Doença de Alzheimer, Metais pesados, Patogênese, Degeneração neural, Intoxicação do sistema nervoso por metais pesados.

\begin{abstract}
Objective: To describe the main pathophysiological changes caused by Heavy Metals (HM) in the body and their possible contribution to the onset and progression of Alzheimer's Disease (AD). Methods: A bibliographical, exploratory research, integrative review type was carried out. Articles published from 2009 to 2021 were included. Results: Chronic exposure to HM has become more common among the world population as the aggressive pace of human activities releases excessive amounts of HM into the environment. Especially non-essential HM disturb the homeostasis of essential HM at the cellular, tissue and organic levels. Increased levels of HM in the body affect brain physiology and immunity, as well as contributing to the abnormal formation of reactive oxygen species in the central nervous system and to toxic protein accumulation such as $\beta$-amyloid protein and tau protein, inducing the process of brain neurodegeneration. Final considerations: Heavy Metals interact with $\beta$-amyloid protein, impair tau protein function and cause overproduction of inflammatory mediators in the brain, which results in aggregation of amyloid plaques in tissue, cell destabilization and neuronal death, which can lead to the onset and progression of AD.
\end{abstract}

Keywords: Alzheimer's disease, Heavy metals, Pathogenesis, Nerve degeneration, Heavy metal poisoning nervous system.

\section{RESUMEN}

Objetivo: Describir los principales cambios fisiopatológicos provocados por los Metales Pesados (MP) en el organismo y su posible contribución al desarrollo o progresión de la Enfermedad de Alzheimer (EA). Métodos: Se trata de una investigación bibliográfica del tipo revisión integradora de la literatura, con carácter exploratorio. Se incluyeron artículos publicados de 2009 a 2021. Resultados: La exposición crónica a MP se ha vuelto más común entre la población mundial a medida que el ritmo agresivo de las actividades humanas

${ }^{1}$ Pontifícia Universidade Católica de Goiás (PUC-GO), Goiânia - GO. *E-mail: soaresfr@icloud.com

2 Universidade Estadual de Goiás (UEG), Goiânia - GO. 
libera cantidades excesivas de MP al medio ambiente. Especialmente los MP no esenciales perturban la homeostasis de los MP esenciales a nivel celular, tisular y orgánico. El aumento de los niveles de MP en el cuerpo afecta la fisiología y la inmunidad del cerebro, además de contribuir a la formación anormal de especies reactivas de oxígeno en el sistema nervioso central y a la acumulación de proteínas tóxicas como la proteína $\beta$-amiloide y la proteína tau que inducen el proceso de neurodegeneración cerebral. Consideracioes finales: Los metales pesados interactúan con la proteína $\beta$-amiloide, deterioran la función de la proteína tau y provocan la sobreproducción de mediadores inflamatorios en el cerebro, lo que resulta en la agregación de placas amiloides en los tejidos, la desestabilización celular y la muerte neuronal, lo que puede conducir al inicio y progresión de la EA.

Palabras clave: Enfermedad de Alzheimer, Metales pesados, Patogénesis, Degeneración nerviosa, Intoxicación del sistema nervioso por metales pesados.

\section{INTRODUÇÃO}

A Doença de Alzheimer (DA) é uma doença neurodegenerativa progressiva e irreversível, relacionada à idade, que leva ao comprometimento da cognição e da memória (HUAT TJ, et al., 2019). O Relatório Mundial de Alzheimer apresentou a estimativa mundial de mais de 50 milhões de pessoas vivendo com essa doença em 2019; podendo aumentar para 152 milhões até 2050 (ADELINA C, 2019). Além da idade e da predisposição genética, outros fatores de risco para o desenvolvimento da DA são exposições ocupacionais, exposição a Metais Pesados (MP) e fatores ambientais diversos como clima, uso de celular, vitamina $\mathrm{D}, \mathrm{pH}$ da água e exposição a campos elétricos e magnéticos (HUAT TJ, et al., 2019; KILLIN LOJ, et al., 2016).

A fisiopatologia da DA é multifatorial, heterogênea, progressiva e interativa (TOBORE OT, 2018). Contudo, as principais alterações patológicas observadas no tecido cerebral de um indivíduo com DA são: a deposição do peptídeo $\beta$-amiloide ( $\beta A$ ), resultado de clivagens sequenciais da Proteína Precursora Amiloide (APP) e a presença da proteína tau hiperfosforilada, o que resulta na desestabilização de microtúbulos celulares e na formação de Emaranhados Neurofibrilares (ENF) (HAMPEL H, et al., 2018; ERATNE D, et al., 2018).

Os MP são classificados, segundo a toxicidade, em MP Essenciais (MPE), dentre eles: Zinco (Zn), Cobre (Cu), Ferro (Fe) e Cobalto (Co) e MP Não Essenciais (MPNE), tais como: Alumínio (Al), Cádmio (Cd), Mercúrio $(\mathrm{Hg})$, Arsênio (As) e Cromio ( $\mathrm{Cr}$ ). Os primeiros, mesmo sendo considerados inofensivos, podem se tornar tóxicos se presentes no organismo em altas concentrações; já os MPNE são considerados tóxicos até em baixas concentrações. Os MPE estão diretamente relacionados à homeostase corporal, influenciando na sobrevivência e crescimento celular, na imunidade corporal, em reações enzimáticas, na síntese de Ácido Desoxirribonucleico (DNA) e vitaminas e no desenvolvimento de órgãos e tecidos (KIM J, et al., 2019).

Sabe-se que a desregulação na homeostase de MPE e a exposição crônica a MPNE têm impacto significativo na patogênese da DA (HUAT TJ, et al., 2019). A natureza e gravidade das alterações celulares variam de acordo com o MP envolvido, os seus níveis de exposição química e estados de valência (inorgânicos ou orgânicos), o modo de exposição (aguda ou crônica), a idade do indivíduo e o tempo de exposição (SHARMA B, et al., 2014; MEZZAROBA L, et al., 2019).

Dessa forma, o objetivo do trabalho foi analisar estudos que descrevam, fisiopatologicamente, os danos que os MP causam a nível celular e sua influência na patogênese da DA. Isso não só facilita o acesso à informação, mas também divulga o conhecimento sobre o assunto e possibilita a realização de futuros estudos mais direcionados sobre o tema.

\section{MÉTODOS}

Trata-se de uma pesquisa bibliográfica do tipo revisão integrativa, de caráter exploratório. Foram utilizadas as bases de dados eletrônicas: PubMed (National Center Biotechnology Information), Portal de Periódicos da Coordenação de Aperfeiçoamento de Pessoal de Nível Superior (CAPES) e Biblioteca Virtual em Saúde (BVS) para realização do levantamento bibliográfico. Na estratégia de busca dos artigos utilizou-se os seguintes Descritores em Ciências da Saúde (DeCS), nos idiomas português e inglês, isolados ou combinados: Alzheimer Disease; Heavy Metal, Environmental factors, Pathophysiology, Neurodegeneration. Foram 
incluídos artigos publicados no período de 2009 a 2021, para abranger artigos de alto impacto e relevância para o tema, com texto completo disponível gratuitos e que estavam relacionados aos objetivos propostos nesta revisão. Foram excluídos os artigos duplicados, os que não apresentaram o texto completo disponível e aqueles que não apresentaram relação com os objetivos propostos pelo estudo.

\section{RESULTADOS E DISCUSSÃO}

Foram encontrados inicialmente 813 artigos. Após a exclusão por duplicação, foi realizada a leitura do título e abstract de todos os artigos selecionados. Em seguida foram selecionados 181 artigos para leitura integral e, ao final, selecionados 32 artigos que se encaixavam no tema proposto e nos critérios de inclusão. O processo de seleção dos artigos é exposto na Figura 1.

Figura 1 - Fluxograma representativo da metodologia desta revisão bibliográfica.

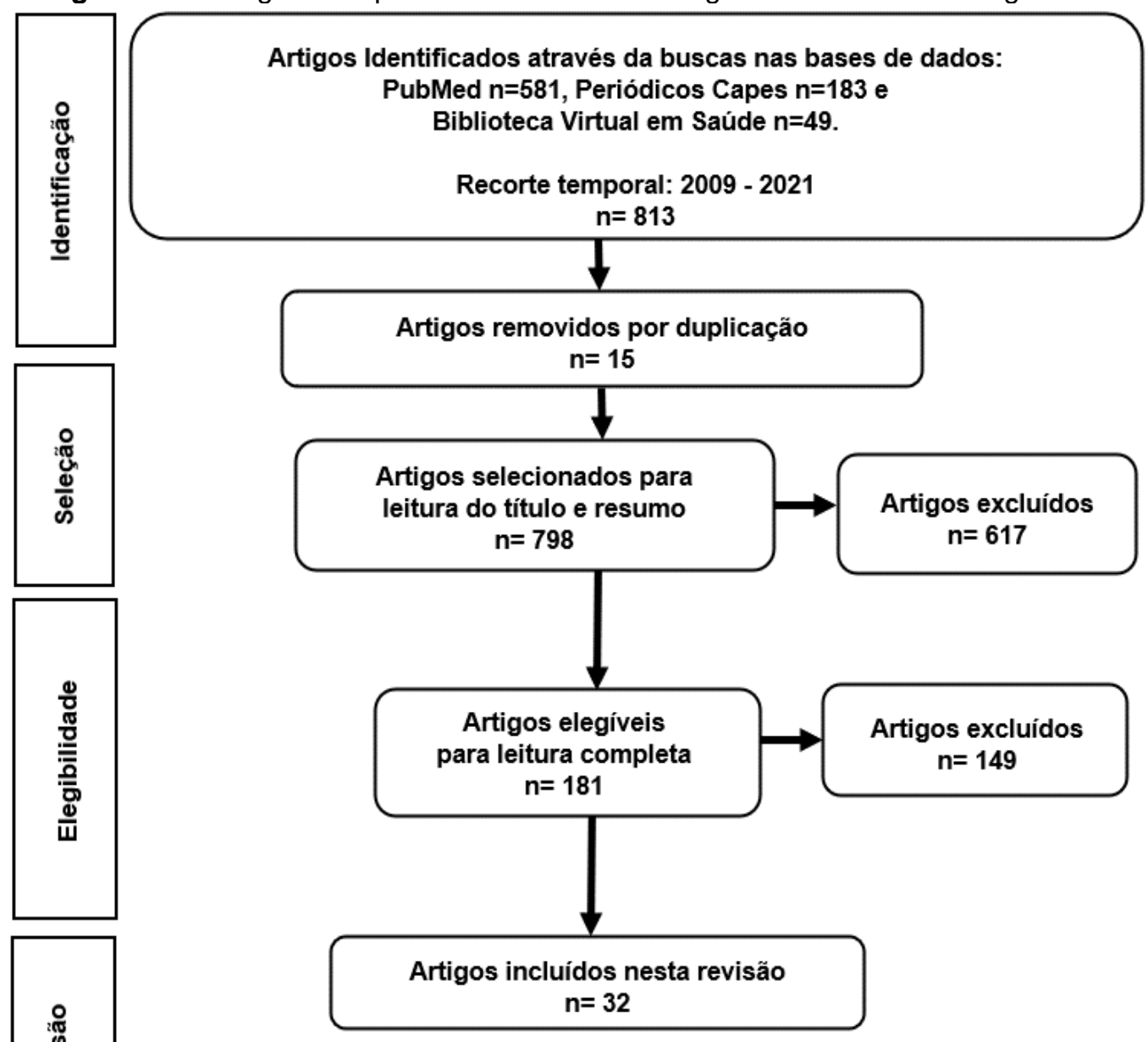

Fonte: Soares FR, et al., 2021.

Os artigos foram lidos na íntegra, revisados, classificados conforme a sua descrição e apresentados no Quadro 1.

A DA é uma doença neurodegenerativa progressiva e irreversível, relacionada à idade, que leva ao comprometimento cognitivo e da memória. Além da idade e da predisposição genética, outros fatores de risco para o desenvolvimento da DA incluem fatores ambientais como a exposição a metais pesados, exposição a substâncias tóxicas ocupacionais e a poluição ambiental. Esses fatores podem desempenhar um papel fundamental no início e na progressão desta doença (KIM J, et al., 2019). 
Quadro 1 - Aspectos gerais dos estudos revisados.

\begin{tabular}{|c|c|c|}
\hline Artigo, ano & Objetivo & Principais achados \\
\hline $\begin{array}{l}\text { ASHOK A, et al., } \\
2015 .\end{array}$ & $\begin{array}{l}\text { Tratar ratos com As, } \mathrm{Cd} \text { e } \mathrm{Pb} \text { em concentrações } \\
\text { detectadas em águas subterrâneas da Índia desde a } \\
\text { gestação até o pós natal. }\end{array}$ & $\begin{array}{l}\text { Os resultados demonstraram um aumento dose-dependente de } \beta \text {-amilóide no córtex frontal e hipocampo logo após } \\
\text { o desmame. Os metais ativaram a via pró-amiloidogênica, mediada pelo aumento da proteína precursora de } \\
\text { amilóide (APP), e subsequente processamento de APP mediado por beta secretase (BACE) e presenilina (PS). Pb } \\
\text { desencadeou a máxima indução de Aß, enquanto o As ou Cd causou aumento da APP, devido à indução reduzida } \\
\text { de BACE e PS. } \\
\text { A exposição ao As, Cd e Pb induz a manifestação prematura de patologia semelhante à DA que é sinérgica e } \\
\text { dependente do estresse oxidativo e da inflamação. }\end{array}$ \\
\hline $\begin{array}{l}\text { CHEIGNON C, et al., } \\
2018 .\end{array}$ & $\begin{array}{l}\text { Revisar a ligação entre estresse oxidativo e DA, e as } \\
\text { consequências para o peptídeo } A \beta \text { e moléculas vizinhas } \\
\text { em termos de dano oxidativo. }\end{array}$ & $\begin{array}{l}\text { Os resultados mostraram que uma característica importante na DA é a presença de danos oxidativos em lipídeos } \\
\text { e proteínas neuronais em particular, o que claramente liga o estresse oxidativo a essa doença. }\end{array}$ \\
\hline $\begin{array}{l}\text { DESHPANDE A, et } \\
\text { al., } 2009 .\end{array}$ & $\begin{array}{l}\text { Mostrar que o acúmulo de oligômeros cerebrais da DA } \\
\text { sintéticos ou nativos nas sinapses é regulado pela } \\
\text { atividade sináptica }\end{array}$ & $\begin{array}{l}\text { A estimulação elétrica ou química aumentou a localização sináptica de AbetaO e aumentou a formação de } \\
\text { oligômeros nos terminais sinápticos, enquanto a inibição com TTX bloqueou a localização sináptica de AbetaO e } \\
\text { reduziu a carga sináptica de AbetaO. }\end{array}$ \\
\hline $\begin{array}{l}\text { EJAZ HW e WANG } \\
\text { W, } 2020 .\end{array}$ & $\begin{array}{l}\text { Apresentar uma melhor compreensão do estado atual } \\
\text { dos íons Cu em várias características da DA. }\end{array}$ & $\begin{array}{l}\text { O complexo Cu-A catalisa a geração de espécies reativas de oxigênio (ROS) e resulta em dano oxidativo. A ligação } \\
\text { dos níveis de cobre na DA ainda é ambígua, pois algumas pesquisas indicam uma deficiência de Cu, enquanto } \\
\text { outras mostram seu maior teor na DA, e por isso há necessidade de aumentar e diminuir seus níveis em modelos } \\
\text { animais, respectivamente, para estudar qual é a causa. }\end{array}$ \\
\hline $\begin{array}{l}\text { FALLER P e } \\
\text { HUREAU C, } 2012 .\end{array}$ & $\begin{array}{l}\text { Analisar a importância dos íons metálicos ativos, Fe e } \\
\text { Cu, no metabolismo do oxigênio e no estresse oxidativo } \\
\text { conectado à Doença de Alzheimer. }\end{array}$ & $\begin{array}{l}\text { Muito pouco se sabe sobre o mecanismo de agregação e o papel que os íons metálicos desempenham, bem como } \\
\text { o mecanismo mais detalhado de produção de ROS por Cu-Ab, e sua dependência do estado de agregação e o } \\
\text { impacto reverso de ROS na agregação e toxicidade neuronal. }\end{array}$ \\
\hline $\begin{array}{l}\text { GIACCONI R, et al., } \\
2017 .\end{array}$ & $\begin{array}{l}\text { Identificar determinantes associados ao Zn plasmático } \\
\text { para compreender como as condições fisiopatológicas } \\
\text { podem afetar a concentração desse metal durante o } \\
\text { envelhecimento. }\end{array}$ & $\begin{array}{l}\text { O decréscimo de Zn no plasma foi mais fortemente previsto pela idade, enquanto correlações positivas foram } \\
\text { encontradas com albumina, RANTES e ingestão de Zn após ajuste para múltiplos fatores de confusão. O genótipo } \\
\text { HSP70 +1267 AA foi um fator independente associado às concentracões plasmáticas de Zn. A relação Cu/Zn foi } \\
\text { positivamente associada a marcadores de inflamação sistêmica e idade e negativamente associada aos níveis } \\
\text { séricos de albumina. }\end{array}$ \\
\hline $\begin{array}{l}\text { GREENOUGH MA, et } \\
\text { al., } 2013 .\end{array}$ & $\begin{array}{l}\text { Discutir o estresse oxidativo/nitrosativo na DA com foco } \\
\text { no papel que os metais desempenham nesse processo. }\end{array}$ & $\begin{array}{l}\text { Os resultados demonstram que perturbações na distribuição de Cu e Zn são importantes para a agregação da } \\
\text { proteína } A B \text { associada com a Doença de Alzheimer. Além disso, níveis elevados de Cu e Fe em sítios de formação } \\
\text { de oligômeros } A B \text { podem promover interações } A b: C u 2+\text { e } A b: F e 3+\text { que levam à geração de } \mathrm{H} 2 \mathrm{O} 2 \text { que, em níveis } \\
\text { elevados, é uma característica da DA. }\end{array}$ \\
\hline $\begin{array}{l}\text { GROMADZKA G, et } \\
\text { al., } 2020 \text {. }\end{array}$ & $\begin{array}{l}\text { Explorar dados sobre o Cu para abrir uma nova área } \\
\text { para potenciais intervenções terapêuticas baseadas na } \\
\text { suplementação ou remoção desse metal em doenças } \\
\text { neurodegenerativas. }\end{array}$ & $\begin{array}{l}\text { Os resultados mostram que o Cu é importante para as células cerebrais como cofator e componente estrutural de } \\
\text { diversas enzimas envolvidas em vias bioquímicas. Entretanto, seu excesso nas células é prejudicial, uma vez que } \\
\text { o Cu ativo redox pode catalisar a produçãao de radicais hidroxila induzindo estresse oxidativo e dano celular; também } \\
\text { pode afetar os processos de agregação de proteínas ou neuroinflamação. }\end{array}$ \\
\hline $\begin{array}{l}\text { HENEKA MT, et } \\
\text { al., 2015. }\end{array}$ & $\begin{array}{l}\text { Prover uma visão atual sobre neuroinflamação durante } \\
\text { a DA. }\end{array}$ & $\begin{array}{l}\text { Os resultados apontam que as interações ligante-receptor que mantêm a microglia sobre um controle rígido no } \\
\text { cérebro normal estão disfuncionais em doenças neurodegenerativas crônicas, mas não se sabe ao certo como e } \\
\text { quando isso acontece. }\end{array}$ \\
\hline $\begin{array}{l}\text { HUANG W, et al., } \\
2017 .\end{array}$ & $\begin{array}{l}\text { Determinar os efeitos da Hiperforina na formação } \\
\text { induzida por Alumínio de } A ß \text { e hiperfosforilação da } \\
\text { proteína tau. }\end{array}$ & $\begin{array}{l}\text { Os resultados mostraram que o tratamento com Hiperforina reduziram significativamente a produção de Aß induzida } \\
\text { por maltolato de alumínio através da redução da expressão de APP, BACE1 e PS1 ao mesmo tempo que aumentou } \\
\text { a expressão de sAPPa, ADAM9/10/17 e fosforilação da proteína tau em células PC12. }\end{array}$ \\
\hline $\begin{array}{l}\text { HUAT TJ, et al., } \\
2019 .\end{array}$ & $\begin{array}{l}\text { Revisar como metais essenciais e não essenciais } \\
\text { afetam a fisiologia e a imunidade do cérebro, bem como } \\
\text { seus papéis no acúmulo de espécies proteicas tóxicas } \\
\text { da } A D \text { (ou seja, } \beta \text {-amilóide e tau). }\end{array}$ & $\begin{array}{l}\text { Os resultados demonstram que a ruptura na homeostase de metais essenciais e o acúmulo de metais não } \\
\text { essenciais perturbam o metabolismo celular, a defesa antioxidante e as respostas imunes, levando ao aparecimento } \\
\text { e progressão da } D A \text {. Na interação de metais e } A \beta \text {, foi observado que os biometais interferem na função da APP e } \\
\text { facilitam a agregação de } A \beta \text { em placas. }\end{array}$ \\
\hline
\end{tabular}

REAS | Vol.15(2) | DOI: https://doi.org/10.25248/REAS.e9454.2022

Página 4 de 12 


\begin{tabular}{|c|}
\hline Artigo, ano \\
\hline KAWAHARA M, \\
2012. \\
\hline KENCHE VB e \\
BARNHAM KJ, 2011. \\
\hline
\end{tabular}

KIM J, et al., 2019.

KUMAWAT KL, et al., 2014.

LI X, et al., 2012.

LING J, et al., 2018

MEZZAROBA L, et al., 2019.

NEWCOMBE EA, et al., 2018.

NOTARACHILLE G, et al., 2014.

NÚÑEZ MT, et al., 2012.

OSHIMA E, et al., 2013.

PHUAGKHAOPONG S, et al., 2017.

\section{Objetivo}

Revisar o entendimento de que a ruptura da homeostase do Ca através dos canais amiloides pode ser a base molecular da neurotoxicidade do $A B$.

Resumir as interações fisiológicas e patológicas que íons metálicos desempenham na função sináptica com ênfase na interação com a proteína $A ß$.

Revisar a toxicidade de metais pesados, as terapias atualmente disponíveis e o papel e a eficácia da terapia de quelação para seu manejo.

Por em prova a hipótese que a micróglia exposta $\mathrm{ao} \mathrm{Pb}$ pode secretar citocinas, resultando em consequente morte neuronal.

Estudar a toxicidade do Cd relacionada à DA em um modelo de camundongo [proteína precursora de amilóide (APP) / camundongos transgênicos presenilina 1 (PS1), transfecção dupla de APP695swe e genes PS1 mutantes].

Explorar o gene e variações envolvidas no processo de desenvolvimento da DA induzida por Mn.

Revisar os efeitos dos metais essenciais $\mathrm{Zn}, \mathrm{Cu}, \mathrm{Mn}$ e Fe sobre o SNC, bem como os mecanismos envolvidos em sua neurotoxicidade.

Demonstrar como a inflamação crônica pode influenciar na suscetibilidade individual à DA.

Avaliar o efeito do Cd, em diferentes concentrações, tanto no canal iônico AbP1-42 incorporado em uma membrana lipídica planar composta de fosfatidilcolina contendo $30 \%$ de colesterol quanto na estrutura secundária de AbP1-42 em ambiente aquoso.

Descrever os mecanismos pelos quais a homeostase do Fe é perdida na DA e outras doenças em que a acumulação de Fe já foi demonstrada.

Esclarecer se a ingestão a longo prazo de Al pode aumentar a agregação da proteína tau em mamíferos.

Investigar os efeitos de concentrações não tóxicas de Cd na produção de IL-6 e IL-8 e os mecanismos envolvidos.

\section{Principais achados}

Os resultados mostram que a oligomerização de $A ß$ aumenta sua neurotoxicidade e sinaptotoxicidade. Eles são incorporados diretamente nas membranas neuronais e formam canais iônicos permeáveis ao cálcio (canais amilóides). Embora o mecanismo molecular preciso da neurotoxicidade do $A B$ permaneça indefinido, a formação de canais amiloides e a resultante elevação anormal dos níveis de cálcio intracelular podem ser o principal evento para a neurodegeneração, considerando que a dishomeostase do cálcio desencadeia várias vias apoptóticas.

Os resultados ressaltam que quando peptídeos $A ß$ interagem com íons metálicos há grande potencial de quebra da homeostase dos metais e também de geração de agregados $A ß$ tóxicos.

Os resultados mostram que os metais pesados são essenciais para diversos processos biológicos, mas são prejudiciais em excesso por induzirem o estresse oxidativo. A terapia de quelação é usada normalmente para tratar a toxicidade de metais. Mostrando que os metais pesados podem ser eficientemente excretados do corpo após o tratamento com agentes de quelação adequados.

Os resultados mostraram que a estimulacão de micróglias de ratos de linhagem BV2 com 10 $\mu \mathrm{M}$ de $\mathrm{Pb}$ resultou em aumento de atividade das vias da quinase regulada por sinal extracelular (ERK) e proteína quinase B (Akt), além da ativação do fator nuclear kappa B.

Os resultados mostraram que o tratamento com $\mathrm{Cd}$ aumentou a latência e a distância da busca da plataforma e reduziu o número de travessias de plataforma. O número e o tamanho das placas senis nos cérebros de camundongos tratados com Cd aumentaram significativamente. Os níveis de A $\beta 1-42$ e íons de zinco livres foram aumentados. A expressão da proteína ADAM10, sAPPa e NEP foi reduzida.

Os resultados promoveram uma nova visão sobre a neurotoxicidade induzida por $\mathrm{Mn}$ e selecionaram moléculas candidatas à prevenção e tratamento da DA induzida por Mn.

Os resultados mostraram que, em níveis baixos, o $\mathrm{Zn}$ suprime a neurotoxicidade induzida por $\beta$-amilóide; no entanto, em níveis elevados, a ligação de $\mathrm{Zn}$ a $\beta$-amilóide pode aumentar a formação de agregação fibrilar de $\beta$ amilóide, levando à neurodegeneração. Altos níveis de $\mathrm{Cu}, \mathrm{Mn}$ e $\mathrm{Fe}$ participam da formação de agregados de $\alpha$ sinucleína em inclusões intracelulares, denominadas Corpos de Lewy, que resultam em disfunção sináptica e sinucleina em inclusões intraceluk
interrupção do transporte axonal.

interrupção do transporte axonal. da DA.

Os resultados mostram que o $\mathrm{Cd}$ é capaz de interagir com o peptídeo AbP1-42 agindo no canal incorporado na membrana, bem como no peptídeo em solução, tanto diminuindo a frequência do canal AbP1-42 quanto em solução formando agregados grandes e amorfos propensos a precipitar. Isso sugere que o $\mathrm{Cd}$ pode interagir diretamente com os AbPs e pode ser um fator de risco na DA.

Os resultados indicam que doenças neurodegenerativas, como a DA, apresentam atividade reduzida do complexo mitocondrial I, acumulação de $\mathrm{Fe}$, estresse oxidativo e inflamação.

Os resultados apontaram que a ingestão a longo prazo de Al têm maiores chances de causar agregação da proteína tau, apoptose e disfunção neuronal em indivíduos que já apresentam um processo patológico envolvendo a agregação de proteína tau.

Concentrações não tóxicas de Cd podem estimular a liberação de IL-6 e IL-8 através da fosforilação da MAPK e ativação do NF-kB. 


\begin{tabular}{|c|c|c|}
\hline Artigo, ano & Objetivo & Principais achados \\
\hline $\begin{array}{l}\text { SENSI SL, et al., } \\
2018 .\end{array}$ & $\begin{array}{l}\text { Descrever o papel da neurodegeneração relacionada à } \\
\text { Doença de Alzheimer e do declínio cognitivo } \\
\text { engatilhados pelo desequilíbrio de dois metais } \\
\text { endógenos: cobre e zinco. }\end{array}$ & $\begin{array}{l}\text { Os resultados apontam que a desregulação de cobre }(\mathrm{Cu}) \text { é encontrada em um subgrupo de pacientes com Doença } \\
\text { de Alzheimer e afeta negativamente o curso da doença; além disso, o zinco cerebral participa na patogênese da } \\
\text { Doença de Alzheimer ao afetar o metabolismo amilóide. }\end{array}$ \\
\hline $\begin{array}{l}\text { SIMUNKOVA M, et } \\
\text { al., } 2019 .\end{array}$ & $\begin{array}{l}\text { Discutir as terapias atuais baseadas em uma estratégia } \\
\text { de drogas multialvos para atingir várias patologias e } \\
\text { bloquear a progressão da patogênese da Doença de } \\
\text { Alzheimer. }\end{array}$ & $\begin{array}{l}\text { Entre o grupo mais promissor de substâncias com potencial atividade contra a Doença de Alzheimer estão os } \\
\text { flavonoides, que possuem, in vitro, atividade antiamiloidogênica e de desestabilização de fibrilas, assim como agir } \\
\text { como quelantes de metais e supressores de estresse oxidativo. }\end{array}$ \\
\hline $\begin{array}{l}\text { TÖNNIES E e } \\
\text { TRUSHINA E, } 2017 .\end{array}$ & $\begin{array}{l}\text { Discutir o papel do estresse oxidativo na disfunção } \\
\text { sináptica na Doença de Alzheimer. }\end{array}$ & $\begin{array}{l}\text { O papel duplo das espécies reativas de oxigênio (ROS) em mecanismos neuroprotetores celulares essenciais } \\
\text { versus os efeitos negativos do aumento incontrolado de ROS deveria ser cuidadosamente considerado ao } \\
\text { desenvolver estratégias que mitiguem o estresse oxidativo em doenças neurodegenerativas. }\end{array}$ \\
\hline $\begin{array}{l}\text { URRUTIA P, et al., } \\
2018 .\end{array}$ & $\begin{array}{l}\text { Analisar os efeitos das citocinas inflamatórias TNF- } \alpha \text { e } \\
\text { IL-6 e lipopolissacarídeo na concentração de ferro } \\
\text { celular e na expressão e abundância de transportadores } \\
\text { de ferro DMT-1 e FPN1 em neurônios, astrócitos e } \\
\text { micróglia de cérebro de ratos. }\end{array}$ & $\begin{array}{l}\text { Os resultados apontam que estímulos inflamatórios aumentaram a expressão de DMT1 em neurônios, astrócitos e } \\
\text { microglia. Estímulos inflamatórios também induziram a expressão de hepcidina em astrócitos e microglia, mas não } \\
\text { em neurônios. A incubação com hepcidina diminuiu a expressão de FPN1 nos três tipos celulares. O resultado final } \\
\text { dessas mudanças foi o aumento do acúmulo de ferro nos neurônios e microglia, mas não nos astrócitos. }\end{array}$ \\
\hline $\begin{array}{l}\text { VAN DUJIN S, et al., } \\
2017 .\end{array}$ & $\begin{array}{l}\text { Investigar a distribuição do ferro cortical frontal na DA e } \\
\text { envelhecimento normal e a relação entre a distribuição } \\
\text { do ferro e o grau de patologia da DA usando córtex } \\
\text { frontal embebido em parafina fixado em formalina de } 10 \\
\text { pacientes com DA, } 10 \text { idosos, } 10 \text { de meia idade e } 10 \\
\text { controles jovens. }\end{array}$ & $\begin{array}{l}\text { Os resultados mostraram que a distribuição de ferro no córtex frontal não foi afetada pelo envelhecimento normal, } \\
\text { mas foi claramente diferente entre os pacientes com DA e controles. A DA mostrou acúmulo de ferro em placas, } \\
\text { micróglia ativada e, nos casos mais graves, nas camadas corticais médias ao longo das fibras mielinizadas. O grau } \\
\text { de acúmulo de ferro alterado foi correlacionado com a quantidade de placas amilóides e patologia tau no mesmo } \\
\text { bloco. A DA e o envelhecimento normal apresentam distribuição diferente de ferro e mielina no córtex frontal. Essas } \\
\text { mudanças parecem ocorrer após o desenvolvimento das características patológicas da DA. }\end{array}$ \\
\hline WANG et al., 2015. & $\begin{array}{l}\text { Avaliar se os níveis de ferro, zinco e cobre no soro estão } \\
\text { desequilibrados na Doença de Alzheimer. }\end{array}$ & $\begin{array}{l}\text { Os resultados indicam que ao investigar oligoelementos, covariantes como idade e sexo devem ser levadas em } \\
\text { consideração nas análises. Diante desses achados, sugeriu-se que a possível alteração dos níveis séricos de zinco } \\
\text { e cobre esteja envolvida na patogênese da DA. }\end{array}$ \\
\hline $\begin{array}{l}\text { XIONG Y, et al., } \\
2013 \text {. }\end{array}$ & $\begin{array}{l}\text { Aprofundar nos mecanismos de fosforilação e inativação } \\
\text { da proteína fosfatase } 2 A \text { (PP2A). }\end{array}$ & $\begin{array}{l}\text { Os resultados mostraram que o zinco induz a inativação de PP2A e hiperfosforilação de tau através da via Src- } \\
\text { dependente, a regulação da homeostase do zinco pode ser uma terapêutica promissora para DA e tauopatias } \\
\text { relacionadas. }\end{array}$ \\
\hline $\begin{array}{l}\text { YARJANLI Z, et al., } \\
2017 .\end{array}$ & $\begin{array}{l}\text { Prover uma revisão para determinar se as } \\
\text { nanopartículas de óxido de ferro (IONPs) podem } \\
\text { ameaçar a viabilidade celular da mesma forma que o } \\
\text { ferro. }\end{array}$ & $\begin{array}{l}\text { Os resultados mostraram que o ferro produz espécies reativas de oxigênio (ROS) e seu acúmulo, o estresse } \\
\text { oxidativo e a agregação de proteínas formam um ciclo de feedback positivo. A liberação de íons de ferro das IONPs } \\
\text { pode resultar no acúmulo de ferro no tecido alvo e, assim, ativar esse feedback. Entretanto, os níveis de toxicidade } \\
\text { induzida por IONPs dependem do tamanho, concentração, carga superficial e do tipo de revestimento e grupos } \\
\text { funcionais de IONPs. Portanto, IONPs podem levar ao acúmulo de ferro, estresse oxidativo e agregação de } \\
\text { proteínas nas células neurais, mas, considerar suas propriedades é crucial. }\end{array}$ \\
\hline $\begin{array}{l}\text { ZHOU CC, et al., } \\
2018 .\end{array}$ & $\begin{array}{l}\text { Tratar ratos desmamados com chumbo em diferentes } \\
\text { concentrações por } 4 \text { semanas. }\end{array}$ & $\begin{array}{l}\text { Os resultados demonstram que a exposição ao chumbo aumentou o acúmulo de } \beta \text {-amilóide (Aß) e a deposição de } \\
\text { placas amilóides no córtex e no hipocampo, aumentou a expressão da proteína precursora de amilóide (APP) e } \\
\text { ativou a via da proteína de ligação ao elemento regulador de esterol } 2 \text { (SREBP2)-beta secretase (BACE1). Além } \\
\text { disso, diminuiu os níveis de colesterol ao aumentar a expressão do receptor-a do fígado X (LXR-a) e do membro } \\
\text { da família de proteínas A1 do transportador de cassete de ligação de ATP (ABCA1) e diminuir a expressão de } 3- \\
\text { hidroxi-3- metilglutaril-CoA redutase (HMG-CR) e receptor de lipoproteína de baixa densidade (LDL-R) em rato } \\
\text { jovem. }\end{array}$ \\
\hline
\end{tabular}

Fonte: Soares FR, et al., 2021. 
Em relação à exposição aos MP, podemos obtê-los por meio de alimentos, água, solo ou ar, entre outras. Algumas fontes de MPE são: refinarias de óleos, encanamentos, armazenamento de água em depósitos envelhecidos, alta suplementação e ingesta. No caso dos MPNE, estes podem ser obtidos por meio de produtos de indústrias têxteis, indústrias de aço, baterias, indústria de tintas e de papel, galvanoplastia, mineração, pesticidas, plásticos, fertilizantes, peixes e erupções vulcânicas. As principais vias de exposição aos MP são a ingestão, a inalação e o contato dérmico (NARJALA RJ, 2020).

A exposição crônica do organismo humano aos diversos tipos de MP induz, em suma, três processos principais que culminam nas alterações fisiopatológicas da DA, sendo eles: alterações do metabolismo oxidativo, quando o Estresse Oxidativo (EO) e Nitrosativo desempenham efeito deletério nas células cerebrais, agregação de $\beta A$ e a formação de ENF e Neuroinflamação (CHEIGNON C, et al., 2018). Esses processos resultam, em última instância, em perda neuronal e neurodegeneração do Sistema Nervoso Central (SNC). Há, portanto, contribuição direta e/ou indireta para o aparecimento ou progressão da DA (MEZZAROBA L, et al., 2019). A Figura 2 esquematiza as principais alterações fisiopatológicas da exposição humana a MP possibilitando o desenvolvimento ou progressão da DA.

Figura 2 - Esquematização das principais alterações fisiopatológicas da exposição humana a Metais Pesados Essenciais e Não Essenciais possibilitando o desenvolvimento ou progressão da Doença de Alzheimer.

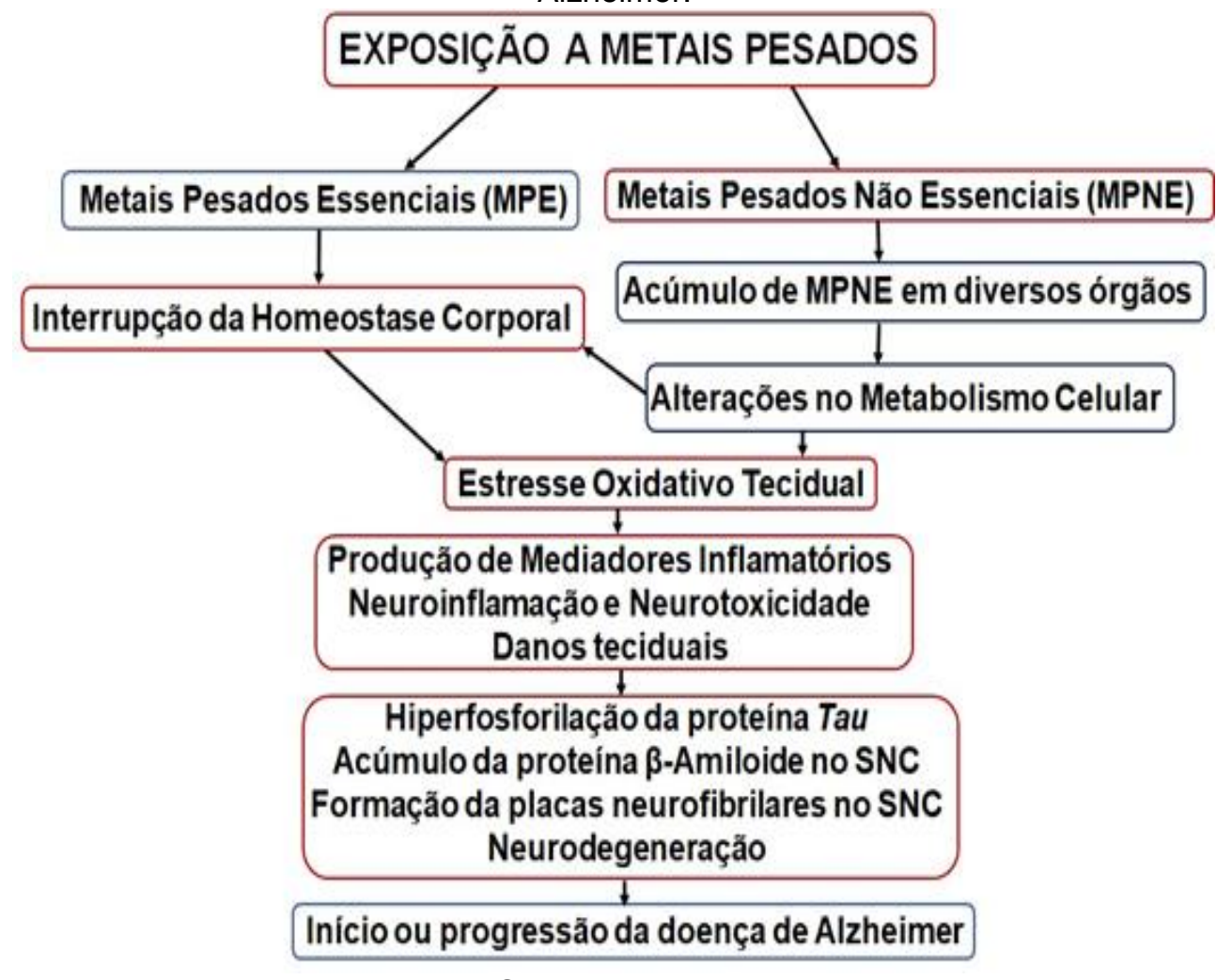

Fonte: Soares FR, et al., 2021.

\section{Alterações do Metabolismo Oxidativo por Metais Pesados}

O EO, desequilíbrio entre compostos oxidantes e antioxidantes, está associado ao rompimento no circuito redox e ao dano macromolecular por aumentar a produção de Espécies Reativas de Oxigênio (ROS), são eles: Radical Ânion Superóxido $\left(\mathrm{O}_{2}^{-}\right)$, Peróxido de Hidrogênio $\left(\mathrm{H}_{2} \mathrm{O}_{2}\right)$, Radical Hidroxila $(\mathrm{OH})$, Óxido Nítrico (ON) e Peroxinitrito (ONOO-). Portanto, o balanço entre a produção de ROS e a defesa oxidante é essencial para uma função celular normal. Na DA, no entanto, há alterações na atividade de enzimas antioxidantes que contribui para o dano oxidativo tecidual (TÖNNIES E e TRUSHINA E, 2017). Além de ser muito importante no mecanismo fisiopatológico, o EO também foi descrito como um dos primeiros eventos que ocasionam danos teciduais na DA (GREENOUGH MA, et al., 2013). 
Um dos principais alvos do dano oxidativo em pacientes com DA é o Ácido Ribonucleico (RNA), devido à uma função defeituosa mitocondrial que leva à produção de ROS e níveis elevados de 8-hidroxiguanina - um marcador sensível de dano oxidativo (SIMUNKOVA M, et al., 2019). Outro mecanismo diz respeito a um aumento nas interações entre metais e moléculas $A \beta$ facilitando a produção de $R O S$, o que se reflete em níveis elevados de peroxidação lipídica, oxidação de DNA, oxidação de proteínas, produtos finais de glicação avançada e espécies reativas de nitrogênio (GREENOUGH MA, et al., 2013).

\section{Danos Oxidativos Induzidos por Metais Pesados}

Íons metálicos como o Zn, Fe, Cu são moduladores de dano oxidativo e já foram encontrados em placas amiloides. Cu e Fe livres são catalisadores muito eficientes da produção de ROS. Reduzidos à $\mathrm{Cu}$ (I) ou Fe (II), por agentes redutores importantes como a glutationa e o ascorbato, esses metais podem reagir, respectivamente, com o oxigênio ou peróxido de hidrogênio e formar superóxido e radicais hidroxila (CHEIGNON C, et al., 2018). É importante ressaltar que a química de coordenação e o local que o metal se encontra determina qual reação será catalisada por ele e que além de terem ação oxidante, esses metais também têm a capacidade de produzir radicais livres e de participar de mecanismos antioxidantes - como é o caso do $\mathrm{Fe}$ na catalase e do $\mathrm{Cu}$ e $\mathrm{Zn}$ na superóxido dismutase, no qual eles clivam o peróxido de hidrogênio e o superóxido, respectivamente, ou seja, o metabolismo desses metais exige um controle rígido (FALLER $P$ e HUREAU C, 2012).

\section{Produção de Espécies Reativas de Oxigênio por Complexos A $\beta$-Metais}

Outro componente importante do EO na DA é a formação de complexos de metais com A $\beta$. Alguns metais são liberados durante a sinapse como, por exemplo, o $\mathrm{Zn}$ - que está presente em altas concentrações na fenda sináptica após ativação de terminais nervosos glutamatérgicos pré-sinápticos - e o Cu. Além deles, outra molécula liberada durante a sinapse é a proteína $A \beta$. A fenda sináptica, portanto, torna-se o lugar onde ocorre interação do $\mathrm{Zn}$ e Cu livres com as moléculas de $A \beta$ formando, respectivamente, os complexos $A \beta-Z n$ e $A \beta-C u$. Enquanto o primeiro está relacionado com a precipitação de $A \beta$ e formação de agregados, o segundo está relacionado com a produção de ROS (KENCHE VB e BARNHAM KJ, 2011). O complexo Aß-Cu tem ação tóxica pela modulação de ciclos de redução-oxidação (redox), em que $\circ \mathrm{H}_{2} \mathrm{O}_{2}$ é o produto responsável pelo $E O$, levando à formação de oligômeros $A \beta$ e sua precipitação nas placas além da peroxidação lipídica citada anteriormente (SENSI SL, et al., 2018).

\section{Agregação de Beta-Amiloides, Formação de Emaranhados Neurofibrilares}

\section{Ferro}

A deficiência na homeostase do ferro causa uma ação excessiva de radicais livres oxigenados. $O$ acúmulo de ferro foi observado dentro e ao redor das placas $A \beta$ e dos ENF justamente por esses serem os principais locais para a reatividade redox catalítica. $O$ excesso de ferro pode levar a alterações na interação entre proteínas de ligação ao elemento de ferro-responsivo (IRPs) e os elementos responsivos ao ferro (IREs) e à interrupção no sequestro e armazenamento de ferro na forma de ferritina (NÚÑ̃Z MT, et al., 2012).

Em condições fisiológicas, o ferro pode se ligar à $A \beta$ e depositá-la como agregados amiloides. Além disso, $A \beta$ nos agregados pode reduzir $\mathrm{Fe}^{3+}$ em $\mathrm{Fe}^{2+}$, levando à formação de mais ROS que por sua vez intensifica a agregação de $A \beta$. Ao remover os íons de ferro das placas $A \beta$, estas têm sua toxicidade reduzida e a solubilidade da proteína $\beta A$ aumenta. Esta explicação mostra um ciclo de feedback positivo entre o acúmulo de ferro, o estresse oxidativo e a agregação de proteínas (YARJANLI Z, et al., 2017).

$O$ ferro e suas proteínas regulatórias, ferritina e transferrina, são altamente encontrados em oligodendrócitos em condições fisiológicas. No entanto, na DA, quantidades substanciais de ferro e ferritina são encontradas dentro das placas $A \beta$, nos ENF e nos vasos sanguíneos. Embora tenha oligodendrócitos contendo ferro e ferritina, a maioria das células associadas aos marcadores da DA com esses componentes são as micróglias (VAN DUJIN S, et al., 2017). Da mesma forma ocorre com a transferrina, que em vez de ter sua distribuição normal nos oligodendrócitos, no cérebro de pacientes com DA ela é distribuída extracelularmente ao redor das placas $A \beta$ e nos astrócitos (HUAT TJ, et al., 2019). 


\section{Cobre}

Níveis elevados de cobre podem levar ao acúmulo de peptídeos $\beta A$ e níveis baixos podem induzir a agregação $A \beta$ (EJAZ HW e WANG W, 2020). O fato do $\mathrm{Cu}^{2+}$ ser reduzido em $\mathrm{Cu}+$ ao se ligar com ao domínio $\mathrm{N}$-terminal da APP pode controlar a função sinaptogênica, estabilidade e metabolismo da proteína e favorecer a remoção de cobre do cérebro. A redução do nível de cobre no cérebro aumenta a proporção de endocitose e processamento de APP e a produção de $A \beta$. Esse $A \beta$ intracelular pode sequestrar cobre, exacerbando 0 desequilíbrio dos níveis desse metal e permitir a agregação de $A \beta$ em placas e gerar dano celular pela formação de ROS $\left(\mathrm{Cu}^{2+}\right.$ reduzido em $\mathrm{Cu}^{+}$gera $\mathrm{H}_{2} \mathrm{O}_{2}$ ) (WANG et al., 2015). Além disso, a proteína tau demonstra atividade redox quando ligada ao cobre facilitando a formação de ENF e o dano oxidativo no cérebro (GROMADZKA G, et al., 2020).

\section{Zinco}

O papel do zinco na DA começou a ser traçado com as observações de sua capacidade de precipitar $A \beta$ - complexo $A \beta-Z n$ - em placas amiloides em concentrações superiores a $300 \mathrm{nM}$. Vale ressaltar que as concentrações de zinco durante a transmissão sináptica se elevam à $300 \mu \mathrm{M}$, e, portanto, é possível que a transmissão sináptica contribua para a deposição de $A \beta$ no cérebro doente (DESHPANDE A, et al., 2009).

$O$ zinco não afeta somente a agregação $A \beta$, mas também os níveis de proteína tau hiperfosforilada e a formação de ENF. Assim como os efeitos do zinco sobre a $A \beta$, baixas concentrações de zinco podem causar a agregação da tau. Além disso, o zinco pode promover a hiperfosforilação da tau indiretamente pela da inativação de fosfatases da tau, como a proteína fosfatase 2A (PP2A) (XIONG Y, et al., 2013).

\section{Chumbo}

Alguns estudos apontam que a exposição aguda ou crônica ao chumbo contribui para a acumulação de $A \beta$, hiperfosforilação da proteína tau e neuroinflamação. Estudo em animais experimentais demonstrou um aumento na expressão de APP e Enzima de Clivagem de APP de Sítio Beta (BACE1), o que induziu uma patologia tipo-DA através do acúmulo de $A \beta$ e formação de placas no hipocampo e córtex (ZHOU CC, et al., 2018).

\section{Alumínio}

Há evidências na literatura que a $A B$ acoplada ao alumínio é altamente tóxico em comparação ao $A B$ normal e que a exposição a esse metal gera o acúmulo de $A B$ em neurônios em cultura ou em cérebros de animais experimentais ou humanos (OSHIMA E, et al., 2013). Também foi demonstrado que a intoxicação crônica por alumínio produz acúmulo de proteína $A B$ e tau em cultura de neurônios do córtex cerebral de rato e que camundongos alimentados com alumínio transfectados com o gene APP humano ( $\operatorname{~g~2576)~exibiram~}$ alterações patológicas semelhantes àquelas do cérebro com DA, incluindo um aumento acentuado na quantidade de $A B$ nas formas secretada e agregada e um aumento na deposição de placas senis (KAWAHARA M, 2012).

\section{Cádmio}

Através de estudos post mortem no cérebro de pacientes com DA, há evidências de que o cádmio está envolvido na agregação de placas $A \beta$ (LI X, et al., 2012). Estudo experimental demonstra que o cádmio é capaz de diminuir a atividade e o turnover do canal AßP 1-42 até que toda a atividade do canal se cesse formando vários agregados amorfos prontos para se precipitar. Essa observação sugere que esse metal pode agir diretamente com o peptídeo AßP implicado na patogênese da DA (NOTARACHILLE G, et al., 2014).

\section{Arsênio}

O arsênio afeta a expressão e processamento do APP em células neuronais e, embora não tenha efeito sozinho na proteína $A \beta$, sua exposição concomitante com chumbo e cádmio demonstrou, em modelos experimentais animais, aumentar a expressão da APP, da BACE1 e proteína presenilin-1 (PSEN1), gerando uma $A \beta$ melhorada (ASHOK A, et al., 2015). 
Em suma, os principais mecanismos pelos quais os MPNE podem contribuir para a patogênese e progressão da DA são apresentados no Quadro 1.

Quadro 1 - Síntese das principais alterações fisiopatológicas induzidas por Metais Pesados Não Essenciais para o desenvolvimento ou progressão da Doença de Alzheimer.

\begin{tabular}{|c|c|c|c|}
\hline $\mathbf{N}$ & Referência & Metal & Principais Alterações \\
\hline 1 & $\begin{array}{l}\text { KAWAHARA M (2010) } \\
\text { OSHIMA E, et al. (2013) }\end{array}$ & Alumínio & $\begin{array}{l}\text { Estimula a produção e agregação de proteína } \beta \text { amiloide no } \\
\text { cérebro. Induz hiperfosforilação da proteína tau. Inibe a } \\
\text { degradação de proteína } \beta \text { amilóide no SNC. Estimula a } \\
\text { produção de citocinas pró-inflamatórias por células gliais. }\end{array}$ \\
\hline 2 & ASHOK A, et al. (2015) & Arsênio & Afeta a expressão e o processamento da PPA. \\
\hline 3 & $\begin{array}{l}\text { LI X, et al. (2012) } \\
\text { NOTARACHILLE G, et } \\
\text { al. (2014) }\end{array}$ & Cádmio & Estimula a agregação de placas $A \beta$. \\
\hline 4 & ZHOU CC, et al. (2018) & Chumbo & $\begin{array}{l}\text { Induz ao estresse oxidativo, disfunção mitocondrial, } \\
\text { excitotoxicidade e agregação } A \beta \text {. }\end{array}$ \\
\hline
\end{tabular}

Fonte: Soares FR, et al., 2021.

\section{Neuroinflamação}

São diversos os fatores que contribuem para a neuroinflamação e neurodegeneração que caracterizam o quadro inflamatório da DA. A neuroinflamação é resultado do dano tecidual causado por compostos neurotóxicos. Durante o processo de neurodegeneração surgem proteínas, tais como: a $\beta A$, tau, proteínas de choque térmico e a cromogranina, que podem agir como padrões moleculares associados a danos teciduais que, a partir da sua interação com receptores celulares de reconhecimento de padrões moleculares, induzem vias moleculares de sinalização inflamatória e, por fim, levam à síntese e secreção de mediadores inflamatórios capazes de provocar lesões teciduais e neurodegeneração (HENEKA MT, et al., 2015).

\section{Ferro}

O excesso de ferro leva a ativação da micróglia pela indução da transcrição mediada pelo fator nuclear $\mathrm{KB}$ (NF-KB) de citocinas pró-inflamatórias como o fator de necrose tumoral- $\alpha$ (TNF- $\alpha$ ) e interleucina-1 $\beta$ (IL-1 $\beta$ ). $O$ acúmulo de sinais inflamatórios como TNF- $\alpha$ e interleucina-6, desencadeia a suprarregulação de Transportador de Metal 1 Divalente (DMT1) e downregulation de ferroportina. Assim, deduz-se que, na inflamação, o acúmulo de ferro nos neurônios e micróglia deve-se também pelas mudanças nos níveis de transportadores de ferro. Ademais, o acúmulo de ferro em macrófagos e micróglia após dano ao SNC foi relacionado a uma mudança na ativação celular em direção a um fenótipo pró-inflamatório resultando numa menor eficiência fagocítica. Mesmo que o mecanismo molecular pelo qual o ferro contribui para a função das células gliais ainda não esteja esclarecido, esses estudos sugerem um ciclo de feedback positivo entre 0 acúmulo de ferro e a pró-inflamação excessiva contribui para a neurotoxicidade (URRUTIA P, et al., 2018).

\section{Cobre}

Foi demonstrado que cobre aumenta o efeito de $A \beta$ na ativação microglial e gera uma subsequente neurotoxicidade. Os complexos de cobre-A $\beta$ induzem a ativação microglial e a liberação de TNF- $\alpha$ e óxido nítrico de forma NF-KB dependente. Ademais, foi demonstrado que a exposição ao cobre-A $\beta$ reduz o fenótipo fagocítico da microglia e aumenta a liberação de TNF- $\alpha$ e IL-1 $\beta$, seguido por uma regulação negativa da expressão da proteína 1 relacionada ao Receptor de Lipoproteína (LRP-1). Níveis reduzidos de LRP-1 prejudicam ainda mais a depuração transcitótica de $A \beta$ e aumentam a neuroinflamação. Além disso, o cobre age como cofator no aumento da potência da toxicidade de $A \beta$ que contribui para uma subsequente ativação da micróglia, que por sua vez expressa a proteína de Menkes - encontrada aumentada pela citocina próinflamatória interferon- $\gamma$, mas não por TNF- $\alpha$ ou IL-1 $\beta$ (NEWCOMBE EA, et al., 2018).

\section{Zinco}

Estudos relatam que o zinco é essencial para a proliferação de células imunes e respostas antioxidantes, adquiridas e inatas. Assim, níveis baixos de zinco estão associados ao aumento da suscetibilidade à infecção 
e à progressão acumulada da doença, afetando a sinalização nas células do sistema imunológico, como a micróglia. Além disso, quando a homeostase do zinco está prejudicada ocorre disfunção imunológica levando ao aumento da inflamação crônica (GIACCONI R, et al., 2017).

\section{Manganês}

A neurotoxicidade do manganês parece estar relacionada ao acúmulo excessivo de ferro por meio da repressão translacional da ferritina APP. O manganês também demonstrou reduzir o Transportador de Glutamato-1 Glial (GLT1), que pode causar neurotransmissão de glutamato sustentada e excitotoxicidade. Além disso, ele induz a ativação da inflamação e disfunção na autofagia, resultando em prejuízo do aprendizado e da memória dependente do hipocampo em camundongos. Estudo recente mostrou que a exposição ao manganês induz a expressão diferencial de genes relacionados à interação citocina-receptor de citocina, apoptose, fosforilação oxidativa, a via de sinalização de receptores do tipo Toll (TLR) e a via de sinalização de insulina em neurócitos. Com isso, sugere-se que mudanças na homeostase do manganês podem gerar mudanças na inflamação e no EO, contribuindo para o desenvolvimento da DA (LING J, et al., 2018).

\section{Chumbo}

A exposição ao chumbo resulta na ativação da micróglia juntamente com a Potenciação de Longo Prazo (LTP) prejudicada e na superprodução de proteínas pró-inflamatórias, como Óxido Nítrico Sintase Induzível (iNOS), IL-1 $\beta$ e TNF- $\alpha$. Esses fatores contribuem para a neurotoxicidade cerebral na DA. O mecanismo de ativação microglial induzida por chumbo envolve a ativação do Fator de Transcrição Nuclear kappa B (NF-kB) e a supra regulação da ciclooxigenase-2. Outras vias microgliais associadas à exposição ao chumbo incluem quinases reguladas por sinal extracelular (ERK) e sinalização de proteína quinase $B$ (AKT). A ativação de TLR por chumbo resulta no aumento da síntese de citocinas pró-inflamatórias e na produção de espécies reativas de nitrogênio e ROS (KUMAWAT KL, et al., 2014).

\section{Alumínio}

Um estudo utilizando a administração oral de alumínio para ratos demonstrou um acúmulo lento e progressivo de tau, maior agregação de tau, apoptose, aumento da ativação glial, resposta inflamatória e disfunção neurológica. Para ter esse efeito, o alumínio aumenta a atividade das tau quinases Quinase 5 Dependente de Ciclina (CDK5) e Glicogênio Sintase Quinase 3 (GSK-3ß), inibindo a desfosforilação da tau e aumentando sua agregação. O alumínio é preferencialmente absorvido pelas células gliais, o que leva a produção de citocinas inflamatórias, incluindo IL-6, e consequentemente induzir a fosforilação de tau por desregulação da cascata CDK5/p35. 293-294 (HUANG W, et al., 2017).

\section{Cádmio}

Os astrócitos humanos tratados com uma concentração não tóxica de cádmio mostraram liberar um nível elevado de IL-6 e IL-8 por meio da ativação da Proteína Quinase Ativada por Mitogênio (MAPK) e das vias de sinalização de NF-kB, levando a neuroinflamação e morte neuronal. Além disso, foi demonstrado que o cádmio induz a citotoxicidade dos astrócitos, aumentando os íons de cálcio intracelular através das vias de sinalização MAPK e Fosfatidilinositol-4,5-bifosfato 3-Quinase (PI3K) / Proteína Quinase B (AKT). Estudos já relataram que o aumento da expressão de IL-6 e IL-8 está associado à patogênese da DA (PHUAGKHAOPONG S, et al., 2017).

\section{CONSIDERAÇÕES FINAIS}

$O$ excesso de MP está diretamente relacionado às alterações patológicas no tecido cerebral de um indivíduo com DA, uma vez que eles interagem com a proteína $\beta A$, prejudicam a função da proteína tau e causam superprodução de mediadores inflamatórios no cérebro resultando na agregação de placas amiloides, desestabilização celular e morte neuronal. Desse modo, expõe-se a necessidade de atenção ao tema pela comunidade científica. Ademais, conforme visto, as principais fontes de contaminação são derivadas de processos industriais e exploração ambiental, por isso é essencial o desenvolvimento de projetos que objetivam diminuir o contato humano com os MP e, com isso, diminuir também a incidência de doenças neurodegenerativas. 


\section{REFERÊNCIAS}

1. ADELINA C. The costs of dementia: advocacy, media and stigma. Alzheimer's Disease International: World Alzheimer Report 2019, 2019; 160p.

2. ASHOK A, et al. Exposure to As- , Cd- , and Pb-Mixture Induces A b , Amyloidogenic APP Processing and Cognitive Impairments via Oxidative Stress-Dependent Neuroinflammation in Young Rats. Toxicol. Sci., 2015; 143(1): 64-80.

3. CHEIGNON C, et al. Oxidative stress and the amyloid beta peptide in Alzheimer's disease. Redox Biology, 2018; 14: 450-464.

4. DESHPANDE $A$, et al. A role for synaptic zinc in activity-dependent a $\beta$ oligomer formation and accumulation at excitatory synapses. Journal of Neuroscience, 2009; 29(13): 4004-4015.

5. EJAZ HW, WANG W. Copper Toxicity Links to Pathogenesis of Alzheimer's Disease and Therapeutics Approaches. Int. J. Mol. Sci., 2020; 21(20): 7660.

6. ERATNE D, et al. Alzheimer's disease: clinical update on epidemiology, pathophysiology and diagnosis. Australasian Psychiatry, 2018; 26(4): 347-357.

7. FALLER P, HUREAU C. A bioinorganic view of Alzheimer's disease: when misplaced metal ions (re)direct the electrons to the wrong target. Chemistry, 2012; 18(50): 15910-15920.

8. GIACCONI R, et al. Main biomarkers associated with age-related plasma zinc decrease and copper/zinc ratio in healthy elderly from ZincAge study. European Journal of Nutrition, 2017; 56(8): 2457-2466.

9. GREENOUGH MA, et al. Metal dyshomeostasis and oxidative stress in Alzheimer's disease. Neurochem. Int., 2013; 62(5): 540-555.

10. GROMADZKA G, et al. Copper Dyshomeostasis in Neurodegenerative Diseases - Therapeutic Implications. International Journal of Molecular Sciences, 2020; 21(23): 9259.

11. HAMPEL H, et al. The cholinergic system in the pathophysiology and treatment of Alzheimer's disease. Brain, 2018; 141(7): 1917-1933.

12. HENEKA MT, et al. Neuroinflammation in Alzheimer's disease. Lancet Neurol., 2015; 14(4): 388-405.

13. HUANG W, et al. Hyperforin attenuates aluminum-induced $A \beta$ production and Tau phosphorylation via regulating Akt/GSK-3 $\beta$ signaling pathway in PC12 cells. Biomedicine and Pharmacotherapy, 2017; 96(59): 1-6.

14. HUAT TJ, et al. Metal Toxicity Links to Alzheimer's Disease and Neuroinflammation. J. Mol. Biol., 2019; 431 (9): $1843-$ 1868.

15. KAWAHARA M. Neurotoxicity of $\beta$-Amyloid Protein: Oligomerization, Channel Formation and Calcium Dyshomeostasis. Current Pharmaceutical Design, 2010; 16(25): 2779-2789.

16. KENCHE VB, BARNHAM KJ. Alzheimer's disease \& metals: therapeutic opportunities. Br. J. Pharmacol., 2011; 163(2): 211-219.

17. KILLIN LOJ, et al. Environmental risk factors for dementia : a systematic review. BMC Geriatrics, 2016; $16(1)$ : 175.

18. KIM J, et al. Journal of Trace Elements in Medicine and Biology Heavy metal toxicity : An update of chelating therapeutic strategies. Journal of Trace Elements in Medicine and Biology, 2019; 54: 226-231.

19. KUMAWAT KL, et al. Acute exposure to lead acetate activates microglia and induces subsequent bystander neuronal death via caspase-3 activation. NeuroToxicology, 2014; 41: 143-153.

20. LI X, et al. The effect of cadmium on A $\beta$ levels in APP/PS1 transgenic mice. Experimental and Therapeutic Medicine, 2012; 4(1): 125-130.

21. LING J,. et al. Identifying key genes, pathways and screening therapeutic agents for manganese-induced Alzheimer disease using bioinformatics analysis. Medicine (United States), 2018; 97(22): e10775.

22. MEZZAROBA L, et al. Neurotoxicology The role of zinc, copper, manganese and iron in neurodegenerative diseases. Neurotoxicology, 2019; 74: 230-241.

23. NARJALA RJ. Heavy Metal Sources and Their Effects on Human Health. IntechOpen, 2020; 12p.

24. NEWCOMBE EA, et al. Inflammation: The link between comorbidities, genetics, and Alzheimer's disease. Journal of Neuroinflammation, 2018; 15(1): 1-26.

25. NOTARACHILLE G, et al. Heavy metals toxicity: Effect of cadmium ions on amyloid beta protein 1-42. Possible implications for Alzheimer's disease. BioMetals, 2014; 27(2): 371-388.

26. NUNEZ MT, et al. Iron toxicity in neurodegeneration. Biometals, 2012; 25(4): 761-776.

27. OSHIMA E, et al. Accelerated tau aggregation, apoptosis and neurological dysfunction caused by chronic oral administration of aluminum in a mouse model of tauopathies. Brain Pathology, 2013; 23(6): 633-644.

28. PHUAGKHAOPONG S, et al. Cadmium-induced IL-6 and IL-8 expression and release from astrocytes are mediated by MAPK and NF-KB pathways. NeuroToxicology, 2017; 60: 82-91.

29. SENSI SL, et al. Copper and Zinc Dysregulation in Alzheimer's Disease. Trends. Pharmacol. Sci., 2018; 39(12): 10491063.

30. SIMUNKOVA M, et al. Management of oxidative stress and other pathologies in Alzheimer's disease. Arch. Toxicol., 2019; 93(9): 2491-2513.

31. TOBORE OT. On The Etiopathogenesis and Pathophysiology of Alzheimer's Disease: A Comprehensive Theoretical Review. Journal of Alzheimer's Disease, 2019; 68(2): 417-437.

32. TÖNNIES E, TRUSHINA E. Oxidative Stress, Synaptic Dysfunction, and Alzheimer's Disease. J. Alzheimers Dis., 2017; 57(4): 1105-1121.

33. URRUTIA P, et al. Inflammation alters the expression of DMT1, FPN1 and hepcidin, and it causes iron accumulation in central nervous system cells. Journal of Neurochemistry, 2013; 126(4): 541-549.

34. VAN DUIJN S, et al. Cortical Iron Reflects Severity of Alzheimer's Disease. Journal of Alzheimer's Disease, 2017; 60(4): 1533-1545.

35. WANG ZX, et al. Serum Iron, Zinc, and Copper Levels in Patients with Alzheimer's Disease: A Replication Study and Meta-Analyses. Journal of Alzheimer's Disease, 2015; 47(3): 565-581.

36. XIONG Y, et al. Zinc induces protein phosphatase $2 A$ inactivation and tau hyperphosphorylation through Src dependent PP2A (tyrosine 307) phosphorylation. Neurobiology of Aging, 2013; 34(3): 745-756.

37. YARJANLI Z, et al. Iron oxide nanoparticles may damage to the neural tissue through iron accumulation, oxidative stress, and protein aggregation. BMC Neuroscience, 2017; 18(1): 1-12.

38. ZHOU CC, et al. Lead exposure induces Alzheimers's disease (AD)-like pathology and disturbes cholesterol metabolism in the young rat brain. Toxicology Letters, 2018; 296: 173-183. 